\title{
CARACTERIZAÇÃO NUTRICIONAL E SENSORIAL DE PREPARAÇÕES COM BAIXO TEOR DE FENILALANINA
}

\section{Viviane Ferreira dos Santos ${ }^{1}$, Luana de Sousa da Silva ${ }^{1}$, Caroline Roberta Freitas Pires $^{2}$ \\ ${ }^{1}$ Graduandos em Nutrição, UFT - Universidade Federal do Tocantins-} Avenida NS 15, 109 Norte - Plano Diretor Norte - Palmas - TO, 77001-090, Brasil email: (viviany_ferreira@uft.edu.br)

${ }^{2}$ Professora Doutora da Universidade Federal do Tocantins - Avenida NS 15, 109 Norte - Plano Diretor Norte - Palmas - TO, 77001-090, Brasil

Recebido em: 08/04/2016 - Aprovado em: 30/05/2016 - Publicado em: 20/06/2016 DOI: 10.18677/Enciclopedia_Biosfera_2016_129

\begin{abstract}
RESUMO
A fenilcetonúria é uma doença hereditária causada pela ausência da enzima fenilalaninahidroxilase, levando ao acúmulo de fenilalanina no sangue e tecidos, neste sentido o portador de fenilcetonúria deverá associar a uma dieta com baixos teores do aminoácido. Este trabalho teve como objetivo avaliar as características nutricionais e sensoriais de duas preparações, sendo um bolo de banana com ameixa e calda de ameixa e um bolo de mandioca com coco. Foram analisados: a composição química, a aceitação e intenção de compra assim como a viabilidade econômica de cada bolo. Ambas as preparações apresentaram baixos teores de proteínas, lipídios e fenilalanina podendo ser destinadas a portadores de fenilcetonúria. As duas formulações apresentaram boa aceitação situando-se entre os termos gostei ligeiramente e gostei muito para os atributos aparência, sabor, aroma e textura, além de apresentarem viabilidade econômica, custando $R \$ 0,29$ a porção do bolo de banana com ameixa e calda de ameixa e $R \$ 0,50$ a porção do bolo de mandioca com coco. Do ponto de vista dietético, ambas as preparações poderão ser incluídas nas refeições diárias de portadores de fenilcetonúria, tornando-se uma boa e nova opção para a alimentação de pessoas com essa patologia.
\end{abstract}

PALAVRAS-CHAVE: bolo, composição química, fenilcetonúria

\section{NUTRITIONAL AND SENSORY CHARACTERIZATION OF PREPARATIONS LOW IN PHENYLALANINE}

\begin{abstract}
Phenylketonuria is a hereditary disease caused by the absence of fenilalaninahidroxilase enzyme, leading to accumulation of phenylalanine in the blood and tissues, in this sense phenylketonuria carrier should involve a diet with low levels of the amino acid. This study aims to evaluate the nutritional and sensory characteristics of two preparations, one banana cake with plum and plum sauce and cassava cake with coconut. We analyzed the chemical composition, acceptance and
\end{abstract}


purchase intent as well as the economic viability of each cake. Both preparations showed low levels of proteins, lipids and phenylalanine may be intended for people with phenylketonuria. The two formulations showed good acceptance standing between terms like slightly and liked for the attributes appearance, flavor and texture, in addition to having economic feasibility, costing $R \$ 0.29$ the portion of banana cake with plum sauce and plum and $R \$ 0.50$ portion of cassava cake with coconut. From a dietary point of view, both preparations may be included in the daily meals of patients with phenylketonuria, making it a good choice for new power people with this disease.

KEYWORDS: cake, chemical composition, phenylketonuria

\section{INTRODUÇÃO}

De origem genética e autossômica recessiva a fenilcetonúria é a doença mais frequente dentre as doenças genéticas de mutação enzimática, acometida por uma desordem metabólica, caracterizada pela deficiência de uma enzima sintetizada no fígado fenilalaninahidroxilase, responsável por converter o aminoácido fenilalanina em tirosina, esse desarranjo metabólico favorece o aumento desse aminoácido a níveis plasmático, gerando uma série de complicações fisiológicas ao indivíduo. (FIGUEIRÓ-FILHO et al., 2004).

Altos índices de fenilalanina no sangue e tecidos levam um quadro clínico específico, como atraso no desenvolvimento neuropsicomotor, hiperatividade, convulsões, alterações cutâneas, agressividade, tremores musculares, microcefalia, descalcificação óssea, crescimento prejudicado e odor característico (ALMEIDA et al., 2007; NALIN et al., 2010).

O teste do pezinho que é realizado até 72 horas depois do nascimento da criança, funciona como um método de busca ativa na detecção dessa patologia. (GARCIA et al., 2007). Sendo essa uma ação obrigatória implantada em todo o território brasileiro, conforme está no Estatuto da Criança e do Adolescente, inciso III do Artigo 10 da Lei no 8069, de 13/07/1990 (BRASIL, 1990).

O Ministério da Saúde visando cumprir os princípios de equidade, universalidade e integralidade por meio da portaria GM/MS № 822, de 06 de Junho de 2001, garante acesso à Triagem Neonatal, buscando a cobertura de $100 \%$ dos recém-nascidos vivos (BRASIL, 2001). A dietoterapia é a forma mais indicada para o tratamento da doença devendo ser mantida durante toda a vida, já que, mesmo após o desenvolvimento neurológico completo do indivíduo, os níveis altos de fenilalanina podem interferir e comprometer as funções neurais (MONTEIRO \& CÂNDIDO, 2006).

Para a boa manutenção do estado físico e neurológico, os portadores de fenilcetonúria deveram seguir uma dieta pobre em proteínas ficando assim permitido aqueles com baixos níveis de fenilalanina sendo essencialmente fonte de carboidratos e lipídios. E proibida a ingestão de alimentos proteicos de origem animal como carnes e derivados, por apresentarem níveis elevados do aminoácido fenilalanina, assim como o grupo das oleaginosas (MONTEIRO \& CÂNDIDO, 2006; MARTINS et al., 2009).

Dada a dificuldade de encontrar nos mercados alimentos específicos para fenilcetonúricos, ressalta-se a importância de estudar e desenvolver receitas que possam ser bem aceitas e incorporadas no dia a dia de quem convive com a patologia, combinando e substituindo alguns alimentos, de forma a mostrar que é possível elaborar receitas saborosas totalmente viáveis. 
Desta forma, o presente trabalho teve por objetivo desenvolver formulações com baixo teor de fenilalanina destinadas a portadores de fenilcetonúria. Diante disso, o objetivo deste trabalho foi o desenvolvimento e a avaliação nutricional e sensorial de duas receitas de bolo com baixo teor de fenilalanina.

\section{MATERIAL E MÉTODOS}

Neste trabalho foram elaboradas duas formulações com baixo teor de fenilalanina, sendo um bolo de banana com ameixa e calda de ameixa e um bolo de mandioca (Tabela 1 e 2). As formulações foram testadas e avaliadas no laboratório Tecnologia de Alimentos da Universidade Federal do Tocantins - UFT.

TABELA 1 - Formulação do bolo de banana com ameixa e calda de ameixa

\begin{tabular}{lcc}
\hline INGREDIENTES & \multicolumn{2}{c}{ QUANTIDADE } \\
\cline { 2 - 3 } & Gramas/mL & Medidas Caseiras \\
\hline Farinha de arroz flocada & 200 & 2 xícaras de chá \\
Amido de milho & 50 & $1 / 2$ xícara de chá \\
Açúcar & 150 & 1 xícara de chá \\
Ameixa seca & 62 & 10 unidades \\
Banana nanica & 257 & 2 unidades $G$ \\
Margarina & 51 & $31 / 2$ colher sopa \\
Fermento & 7 & $11 / 2$ colher de sopa \\
Canela em pó & 1 & $1 / 2$ colher de chá \\
Emulsificante & 5 & 1 colher de chá \\
Água & 272 & $11 / 2$ xícara de chá \\
\hline CALDA & & \\
\hline Ameixa seca & 67 & 10 unidades \\
Açúcar & 52 & 4 colheres de sopa \\
Amido de milho & 15 & 2 colheres de sopa \\
Água & 270 & 1 xícara de chá \\
\hline
\end{tabular}

TABELA 2- Formulação de bolo de mandioca

\begin{tabular}{lcc}
\hline \multirow{2}{*}{ INGREDIENTES } & \multicolumn{2}{c}{ QUANTIDADE } \\
\cline { 2 - 3 } & Gramas/ mL & Medidas caseiras \\
\hline Mandioca crua ralada & $503 \mathrm{~g}$ & 5 xícaras de chá \\
Leite de coco & $200 \mathrm{~mL}$ & Uma garrafinha \\
Flocos de coco & $50 \mathrm{~g}$ & $1 / 2$ xícara de chá \\
Açúcar cristal & $180 \mathrm{~g}$ & 1 xícara de chá \\
Emulsificante & $15 \mathrm{~g}$ & 1 colher de sopa \\
Margarina & $50 \mathrm{~g}$ & $31 / 2$ de sopa \\
Fermento químico & $7 \mathrm{~g}$ & $11 / 2$ de sopa \\
Água & $300 \mathrm{~mL}$ & $11 / 2$ copo americano \\
Amido de milho & $40 \mathrm{~g}$ & $1 / 2$ xícara \\
\hline
\end{tabular}

Para confecção do bolo de banana com ameixa foram acrescentados a uma vasilha de plástico a farinha de arroz flocada, o amido de milho e a canela, ligeiramente misturados e reservados. Em sequência foram batidos no liquidificador em velocidade alta a ameixa, a banana, a margarina o emulsificante e a água, por 
aproximadamente cinco minutos e em seguida despejado junto à vasilha contendo a farinha de arroz, o amido de milho e a canela, após homogeneização foi acrescentando o fermento em pó e misturado delicadamente, após esse processo a massa pronta foi colocada em uma forma redonda de alumínio com furo no meio, devidamente untada com margarina e amido de milho e levada ao forno previamente aquecido por 10 minutos a uma temperatura de $240 \mathrm{gr}$ aus por aproximadamente 45 minutos. A calda foi feita batendo no liquidificador em velocidade alta a ameixa, 0 açúcar, o amido de milho e a água por aproximadamente dois minutos e na sequência a calda foi disposta em uma panela de alumínio e levada ao fogo médio para ser aquecida, mexendo sempre até ferver por um tempo médio de sete minutos.

$\mathrm{Na}$ fabricação do bolo de mandioca com coco, foram batidos na batedeira em velocidade média o leite de coco, o emulsificante, a margarina, o açúcar e a água até dobrar de volume e obter-se uma consistência cremosa, a mandioca crua foi ralada e acrescentada ao creme juntamente com os flocos de coco, o fermento químico e o amido de milho, e em seguida despejados em um tabuleiro retangular untado com margarina e amido de milho e levado ao forno pré-aquecido por 10 minutos a uma temperatura de $240^{\circ}$ graus por 60 minu tos.

\section{Análise Sensorial}

Os testes de aceitação foram realizados na Faculdade ITOP de Palmas TO, com 58 julgadores não treinados, homens e mulheres com idade superior a 18 anos, consumidores de bolo. As formulações foram avaliadas no mesmo dia da elaboração. Cada julgador recebeu uma fatia de bolo em prato descartável, codificado com números de 3 dígitos, juntamente com um copo com água para a limpeza do palato. Os consumidores foram orientados como deveriam proceder para avaliação do produto bem como a maneira correta de preencher a ficha de análise sensorial. Avaliaram-se os atributos aparência, aroma, sabor, textura e impressão global, utilizando escala hedônica de 9 pontos, tendo por extremos as expressões "desgostei extremamente" (1) e "gostei extremamente" (9) (CHAVES \& SPROESSER, 2002). A intenção de compra do produto foi avaliada através de uma escala de cinco pontos, onde 1 equivale a certamente não compraria e 5 certamente compraria.

Obtidas as notas que os provadores atribuíram às amostras, foram determinados os valores médios de cada atributo e em seguida a contagem dos julgadores que atribuíram as notas de acordo com os intervalos adotados (1 a 4; 5 e 6 a 9). Foram obtidos os histogramas de frequência de acordo com os escores de aceitação.

\section{Análise nutricional e viabilidade econômica}

Foi usada a Tabela Brasileira de Composição de Alimentos (TACO) para estimativa de nutrientes e energia (NEPA, 2016). E foram usados dados de estudos científicos publicados para avaliar alimentos não encontrados na tabela. Afim de obter a quantidade energética da porção de cada preparação, foi acatada a soma total de cada macronutriente e multiplicado pela quantidade de energia por $\mathrm{kg}$ de peso que cada um proporciona considerando os fatores de conversão de Atwater. $\mathrm{Kcal}=(4 \times \mathrm{g}$ de carboidratos $)+(9 \times \mathrm{g}$ de lipídios $)+(4 \times \mathrm{g}$ de proteínas) (MAHAN \& ESCOTT-STUMP, 2002).

Também foi obtido o valor da porção das formulações com intuito de verificar a viabilidade econômica. Para cada preparação foi considerado o valor de acordo ENCICLOPÉDIA BIOSFERA, Centro Científico Conhecer - Goiânia, v.13 n.23; p. 1460 
com a quantidade de matéria-prima utilizada na fabricação de cada bolo.

\section{RESULTADOS E DISCUSSÃO}

Os atributos sensoriais e seus valores médios para o bolo de banana com ameixa e calda de ameixa e para o bolo de mandioca com coco ambos com baixo teor de fenilalanina estão descritos na tabela 1.

TABELA 1- Valores médios para os atributos sensoriais das preparações com baixo teor de fenilalanina.

\begin{tabular}{lcc}
\hline \multirow{2}{*}{ Atributos } & \multicolumn{2}{c}{ Formulações } \\
\cline { 2 - 3 } & Bolo de banana com ameixa & Bolo de mandioca \\
\hline Aparência & 7,07 & 7,80 \\
Aroma & 7,24 & 7,65 \\
Sabor & 6,93 & 7,48 \\
Textura & 6,84 & 7,43 \\
Impressão Global & 7,03 & 7,60 \\
Intenção de compra & 3,93 & 4,30 \\
\hline
\end{tabular}

Diante dos dados obtidos pode-se analisar que os valores médios não apresentaram grandes variações para os atributos sensoriais analisados para o bolo de banana com ameixa e calda de ameixa. Para o atributo aparência (Figura 1a) obteve-se média satisfatória de aceitação, onde $84,48 \%$ (49) dos provadores atribuíram notas superiores a 6 . A intensificação da cor é uma questão decisiva para impressão e avaliação positiva do consumidor em relação ao produto, pois antes de experimentar qualquer percepção gustativa, ocorre inicialmente a sedução pela visão, que quase sempre estar associada a alimentos coloridos, vistosos e atraentes (PRADO \& GODOY, 2007).

O atributo aroma obteve nota média de 7,24 (Tabela 1) situando-se entre os termos "gostei moderadamente e gostei extremamente com aceitação de 89,66\% (52) dos provadores. Para o atributo sensorial sabor obteve-se média de 6,93, onde 48 pessoas atribuíram nota superior a 6 . Esses resultados satisfatórios podem ser atribuídos ao aroma e pigmentação da banana após o processo de cocção, conferindo assim um aroma acentuado e agradável. Os aromas naturais são obtidos, após a submissão dos alimentos a tratamento térmico adequado, com torrefação e cocção, ou por métodos físicos, microbiológicos e enzimáticos, sendo esses na maioria alimentos que apresentam substâncias odoríferas e ou sápidas, que após esse processo liberam de forma acentuada o aroma próprio de cada alimento (ANVISA, 2007).

Para o bolo de mandioca com coco o atributo sabor obteve nota média de 7,48 , onde $92,59 \%$ (50) dos provadores atribuíram notas entre os termos gostei ligeiramente a gostei extremamente. A boa aceitação de bolo de mandioca pode ser atribuída, pelo fato de ser um dos alimentos preferenciais na mesa dos brasileiros. (BORGES et al., 2002). Para o atributo sensorial textura, observou-se que o bolo de mandioca apresentou uma boa aceitação, visto que, 92,45\% (49) dos provadores atribuíram notas entre os termos gostei moderadamente e gostei muito da consistência (Figura 1d). 

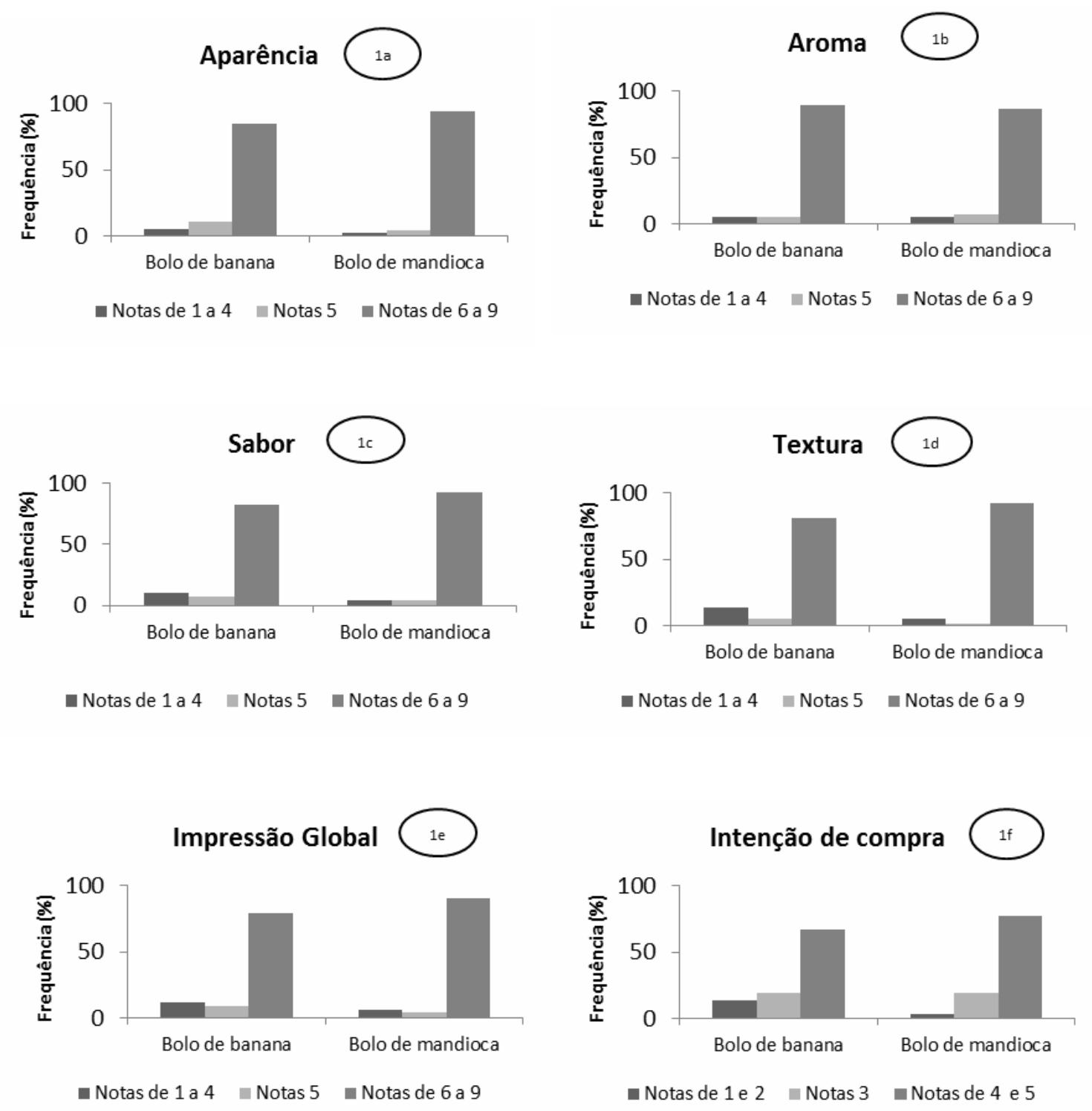

FIGURA 1- Histogramas de frequência dos escores de aceitação dos atributos avaliados para o bolo de banana com ameixa e calda de ameixa e para o bolo de mandioca com coco com baixo teor de fenilalanina.

Ambas as preparações apresentaram boa aceitação quanto a avaliação do atributo impressão global, com $79,31 \%$ e $90,38 \%$ para o bolo de banana com ameixa e calda de ameixa e para o bolo de mandioca com coco respectivamente (Figura 1e). Para a intenção de compra, ambas as preparações tiveram médias satisfatórias sendo que $66,67 \%$ (38) dos provadores afirmaram que provavelmente ou certamente comprariam o bolo de banana com ameixa e calda de ameixa, e 77,36\% (41) disseram que provavelmente ou certamente comprariam o bolo de mandioca com coco (Figura 1f).

Desta forma os dados encontrados no presente estudo corroboram com os dados obtidos por VILAR \& CASTRO (2013) ao avaliarem uma preparação de bolo de maracujá com calda de chocolate destinada para portadores de fenilcetonúria, onde obtiveram $92 \%$ de aceitação. Para análise econômica e sensorial as preparações tiveram boa aceitação e baixo custo, com valores de $R \$ 0,29$ para a porção do bolo de banana e $R \$ 0,50$ para a porção do bolo de mandioca com coco, ENCICLOPÉDIA BIOSFERA, Centro Científico Conhecer - Goiânia, v.13 n.23; p. 1462 2016 
condizendo com os valores encontrados por VILAR \& CASTRO (2013) e AZEVEDO et al. (2015) ao avaliarem preparações destinadas a portadores de fenilcetunúria encontrando respectivamente um valor final de $R \$ 0,97$ para a porção do bolo de maracujá com calda de chocolate e de 0,37 para a porção de um bolo de limão à base de farinha de arroz.

RAMOS et al. (2012) ao desenvolverem mistura para bolos à base de arroz, constataram no estudo que as preparações a partir dessa massa tiveram nota satisfatória, tendo boa aceitação por parte dos provadores, concluindo que a substituição da massa de trigo pela massa de arroz não afetou a aceitação do produto.

Para a determinação indireta da composição nutricional, os cálculos foram feitos a partir dos dados contidos na tabela de composição de alimentos TACO e para o cálculo estimativo do teor de fenilalalanina foram consultados os dados disponíveis no site da ANVISA, e os dados não listados nas tabelas de composição de alimentos ou na ANVISA foram pesquisados em trabalhos científicos publicados.

Informações referentes à composição nutricional do bolo de banana com ameixa e calda de ameixa e do bolo de mandioca com baixo teor de fenilalanina estão inseridas nas tabelas 3 e 4.

TABELA 3 - Composição nutricional por porção $(65 \mathrm{~g})$ do bolo de banana com ameixa e calda de ameixa.

\begin{tabular}{ccccccc}
\hline $\begin{array}{c}\text { ENERGIA } \\
\text { kcal }\end{array}$ & $\begin{array}{c}\text { PTN } \\
(\mathrm{g})\end{array}$ & $\begin{array}{c}\text { CHO } \\
(\mathrm{g})\end{array}$ & $\begin{array}{c}\text { LIPÍDIOS } \\
(\mathrm{g})\end{array}$ & $\begin{array}{c}\text { FIBRAS } \\
(\mathrm{g})\end{array}$ & $\begin{array}{c}\text { SÓDIO } \\
(\mathrm{mg})\end{array}$ & $\begin{array}{c}\text { FENILALANINA } \\
(\mathrm{mg})\end{array}$ \\
\hline 130 & 0,53 & 33,31 & 2,69 & 0,60 & 48,85 & 24,61 \\
\hline
\end{tabular}

TABELA 4 - Composição nutricional por porção $(65 \mathrm{~g})$ do bolo de mandioca.

\begin{tabular}{ccccccc}
\hline $\begin{array}{c}\text { ENERGIA } \\
\text { kcal }\end{array}$ & $\begin{array}{c}\text { PTN } \\
(\mathrm{g})\end{array}$ & $\begin{array}{c}\text { CHO } \\
(\mathrm{g})\end{array}$ & $\begin{array}{c}\text { LIPÍDIOS } \\
(\mathrm{g})\end{array}$ & $\begin{array}{c}\text { FIBRAS } \\
(\mathrm{g})\end{array}$ & $\begin{array}{c}\text { SÓDIO } \\
(\mathrm{mg})\end{array}$ & $\begin{array}{c}\text { FENILALANINA } \\
(\mathrm{mg})\end{array}$ \\
\hline 150 & 0,68 & 25,03 & 6,82 & 0,90 & 57,91 & 30,97 \\
\hline
\end{tabular}

Ao analisar as duas tabelas é possível observar que nas duas preparações o teor de carboidrato é elevado, tendo em vista que a dieta de um fenilcetonúrico é restrita de proteína. Já o teor de fenilalanina é baixo, devido a não utilização de produtos lácteos, trigo e ovos. MAURícIO et al. (2012) ao avaliarem a composição nutricional de receitas de bolo de cenoura destinados a celíacos afirmaram que bolos elaborados com farinha de arroz apresentaram baixo teor protéico quando comparados com formulações com trigo. No entanto o presente estudo teve os níveis de proteína ainda mais reduzidos, visto que a única restrição do celíaco é o glúten.

Valores superiores para lipídios foram encontrados na preparação do bolo de mandioca com coco do que na preparação do bolo de banana com ameixa, com 6,82 gramas para uma porção de 65 gramas. AZEVEDO et al. (2015) encontraram um valor de 7,13 gramas para uma porção de 30 gramas na preparação de um bolo de limão com baixo teor de fenilalanina.

Apesar do baixo valor de fibra alimentar encontrado em ambas as preparações, $0,90(\mathrm{~g})$ e $0,68(\mathrm{~g})$ na porção do bolo de mandioca e do bolo de banana com ameixa, respectivamente, os valores encontrados no presente estudo são superiores quando comparados aos valores encontrados por AZEVEDO et al. (2015) de 0,47 (g) de fibra alimentar para o bolo de limão. 
Para os valores de fenilalanina foram encontrados 24,61 (mg) em uma porção de 65 (g) para o bolo de banana com ameixa e de 30,97 (mg) em uma porção de 65 (g) para o bolo de mandioca, sendo estes teores inferiores aos valores diários de referência para a ingestão de fenilalanina por fenilcetonúricos (SILVA et al., 2012).

\section{CONCLUSÕES}

Diante dos resultados obtidos conclui-se que as formulações elaboradas são viáveis, pois apresentaram boa aceitação sensorial, baixo custo do ponto de vista econômico e de fácil preparo.

Do ponto de vista dietético, ambas as preparações poderão ser incluídas nas refeições diárias de portadores de fenilcetonúria, pois oferece aporte nutricional e valores adequados de fenilalanina, tornando-se uma boa e nova opção para a alimentação de pessoas com essa patologia.

\section{REFERÊNCIAS}

ALMEIDA, M.F. Consenso para o tratamento nutricional de fenilcetonúria. Sociedade Portuguesa de Doenças Metabólicas. Acta Pediátriatrica Portuguesa, Portugal, v.38, n.1, p. 44-54, 2007. Disponível em: <http://www.spdm.org.pt/wpcontent/uploads/2013/10/APP_VOL_38_N1_CR_Tratamento_Nutricional_fenilcetonu ria.pdf> Acesso: 12 de Out. 2015.

ANVISA- Agência Nacional de Vigilância Sanitária. Procedimento pra indicação do uso de aromas na rotulagem de alimentos. Informe técnico $n^{\circ} 26$, de 14 de Junho de 2007. Acesso: 15 de Ago. 2015.

AZEVEDO, L. A.; BORGES, J. S.; PIRES, C. R. F. MONTEIRO, D. C. B.; SOUSA. W. C. Desenvolvimento e avaliação nutricional de preparações para fenilcetonúricos. Enciclopédia Biosfera, Centro Científico Conhecer - Goiânia, v.11 n.21; p. 3385, 2015. Disponível

em: <http://www.conhecer.org.br/enciclop/2015b/saude/desenvolvimento.pdf> Acesso: 15 de Ago. 2015.

BORGES, M. F.; FUKUDA, W. M.G.; ROSSETTI, A. G. Avaliação de variedades de mandioca para consumo humano. Pesquisa Agropecuária Brasileira, Brasília, v. 37, n. 11, p. 1559-1565, nov. 2002. Disponível em: <https://seer.sct.embrapa.br/index.php/pab/article/view/6502/3559> Acessado: 01 de Fev. 2016.

BRASIL. Ministério da Saúde. Portaria GM/MS n²2, de 06 de junho de 2001. Institui no âmbito do Sistema Único de Saúde o Programa Nacional de Triagem Neonatal/PNTN. Diário Oficial da União. 7 de junho de 2001. Disponível em: <http://bvsms.saude.gov.br/bvs/saudelegis/gm/2001/prt0822_06_06_2001.html> Acessado: 10 de Nov. 2015.

BRASIL. Estatuto da criança e do adolescente. Lei 8.069, de 13 de Julho de 1990 e legislação correlata [recurso eletrônico]. 9. ed. Brasília. Câmara dos Deputados, Edições Câmara, 2012. Disponível em: <http://www.crianca.mppr.mp.br/arquivos/File/publi/camara/estatuto_crianca_adolesc ente_9ed.pdf > Acesso: 11 de Nov. 2015. 
CHAVES, J. B. P.; SPROESSER, R. L. Práticas de laboratório de análise sensorial de alimentos e bebidas. Viçosa, MG: Universidade Federal de Viçosa, 2002. $81 \mathrm{p}$.

FIGUEIRÓ-FILHO, E. A.; LOPES, A. H. A.; SENEFONTE, F. R. A.; SOUZA JÚNIOR, V. G.; BOTELHO, C. A.; DUARTE, G. Fenilcetonúria Materna: Relato de caso. Revista Brasileira de Ginecologia e Obstetrícia, Campo Grande, v.26, n.10, p. 813-817, 2004. Disponível

em: $<$ http://www.scielo.br/scielo.php?script=sci_arttext\&pid=S010072032004001000009> Acesso: 23 de Ago. 2015. doi: org/10.1590/S010072032004001000009

GARCIA, M.G.; FERREIRA, E.A.P.; OLIVEIRA, F.P.S. Análise da compreensão de pais acerca do teste do pezinho. Revista Brasileira de Crescimento e Desenvolvimento Humano, São Paulo, v.17, n.1 p. 01-12, 2007. Disponível em: <http://pepsic.bvsalud.org/pdf/rbcdh/v17n1/01.pdf> Acesso: 06 de Jan. 2016.

MARTINS, F.F.; MENDES, A.B.; CRUZ, W.M.S.; BOAVENTURA, G.T. Metabolismo do cálcio na fenilcetonúria. Revista de Nutrição, Campinas, v.22, n.3, p. 419-428, 2009. Disponível em: <http://www.scielo.br/pdf/rn/v22n3/v22n3a12.pdf> Acesso: 14 de Dez. 2015.

MAURÍCIO, A.A.; BUCHARLES,P.B.; BOLINI, H.M.A.; SOUSA, V.M.C. Bolo de cenoura com e sem glúten: desenvolvimento da formulação e aceitação do produto. Revista Agro@mbienteOn-line, v. 6, n. 3, p. 250-257, 2012. Disponível em: <http://saes2010.ufrr.br/index.php/agroambiente/article/view/703> Acesso: 11 de Ago. 2015. DOI: http://dx.doi.org/10.18227/1982-8470ragro.v6i3.703.

MONTEIRO, L.T.B.; CÂNDIDO, L.M.B. Fenilcetonúria no Brasil: evolução e casos. Revista de Nutrição, Campinas, v. 19, n. 3, p. 381-387, 2006. Disponível em: <http://www.scielo.br/pdf/rn/v19n3/30143.pdf> Acesso: 20 de Set. 2015.

NALIN, T.; PERRY, I.D.S.; REFOSCO, L.F.; NETTO, C.B.O.; SOUZA, C.F.M.; VIEIRA, T.A.; PICON, P.D.; SCHWARTZ, I.V.D. Fenilcetonúria no Sistema Único de Saúde: avaliação de adesão ao tratamento em um centro de atendimento do Rio Grande do Sul. Revista HCPA, Porto Alegre, v.30, n. 3, p.225-232, 2010. Disponível em: <http://seer.ufrgs.br/index.php/hcpa/article/view/15435/9693> Acessado: 06 de Jan.2016.

PRADO, M.A.; GODOY, H.T. Teores de corantes artificiais em alimentos determinados por cromatografia líquida de alta eficiência. Química Nova, São Paulo, v. 30, n. 2, p. 268-273, 2007. Disponível em: <http://www.scielo.br/pdf/qn/v30n2/04.pdf> Acesso: 19 de Set. 2015.

RAMOS, N.C.; PIEMOLINI-BARRETO, L.T.; SANDRI, I.G. Elaboração de prémistura para bolo sem glúten. Alimentos e Nutrição, Araraquara, v. 23, n. 1, p. 3338, 2012. Disponível em: <http://servbib.fcfar.unesp.br/seer/index.php/alimentos/article/viewFile/1612/1202> Acesso: 16 de Dez. 2015. 
SILVA, A.R.Z.; BELLANDA,B.C.R.; AMARAL, É.B.; GOMES, N.B. Elaboração de produto alimentício similar à gelatina destinada aos indivíduos com fenilcetonúria. Cadernos das Escolas de Saúde, Brasília, v. 1, n. 7, p. 1-11, 2012. Disponível em: <http://www.unibrasil.com.br/pdf/nutricao/2011-2/2_tcc.pdf> Acessado: 15 de Nov. 2015.

UNIVERSIDADE DE CAMPINAS. Núcleo de Estudos e Pesquisa em Alimentação. Tabela Brasileira de Composição de Alimentos. Versão II. $2^{\underline{a}}$ ed. Campinas, SP: Unicamp; $2006.2113 p . \quad$ Disponível <http://www.unicamp.br/nepa/taco/contar/taco_versao2.pdf> Acesso: 17 de Ago. 2015.

VILAR, J. S.; CASTRO, T. C. M. Análise sensorial de bolo de maracujá com chocolate para fenilcetonúricos. Revista Vértices, Rio de Janeiro, v.15, n. 1, p. 6975 , 2013. em: $<$ http://essentiaeditora.iff.edu.br/index.php/vertices/article/view/18092667.20130007/2739 > Acesso: 28 de Nov. 2015. DOI: 10.5935/18092667.20130007 